\title{
A Paleolithic diet confers higher insulin sensitivity, lower C-reactive protein and lower blood pressure than a cereal-based diet in domestic pigs
}

\author{
Tommy Jönsson*1, Bo Ahrén ${ }^{1}$, Giovanni Pacini², Frank Sundler ${ }^{3}$, \\ Nils Wierup ${ }^{4}$, Stig Steen ${ }^{5}$, Trygve Sjöberg ${ }^{5}$, Martin Ugander 6 , \\ Johan Frostegård7 , Leif Göransson ${ }^{8}$ and Staffan Lindeberg ${ }^{1}$
}

\begin{abstract}
Address: ${ }^{1}$ Department of Clinical Sciences, Lund University, Box 117, 22100 Lund, Sweden, ${ }^{2}$ Metabolic Unit, Institute of Biomedical Engineering National Research Council, Corso Stati Uniti, 4, 35127 Padova, Italy, ${ }^{3}$ Department of Experimental Medical Science, Lund University, Box 117, 22100 Lund, Sweden, ${ }^{4}$ Department of Physiological Sciences, Lund University, Box 117, 22100 Lund, Sweden, ${ }^{5}$ Department of Cardiothoracic Surgery, Heart-Lung Division, Lund University, Box 117, 22100 Lund, Sweden, ${ }^{6}$ Department of Clinical Physiology, Lund University, Box 117, 22100 Lund, Sweden, ${ }^{7}$ Department of Medicine, CIM, Karolinska University Hospital, Huddinge, 14186 Stockholm, Sweden and ${ }^{8}$ The Swedish Farmers Supply and Crop Marketing Association, Box 30192, 10425 Stockholm, Sweden

Email: Tommy Jönsson* - Tommy.Jonsson@med.lu.se; Bo Ahrén - Bo.Ahren@med.lu.se; Giovanni Pacini - giovanni.pacini@isib.cnr.it; Frank Sundler - Frank.Sundler@mphy.lu.se; Nils Wierup - nils.wierup@mphy.lu.se; Stig Steen - stig.steen@thorax.lu.se;

Trygve Sjöberg - Trygve.Sjoberg@med.lu.se; Martin Ugander - martin.ugander@med.lu.se; Johan Frostegård - Johan.Frostegard@medhs.ki.se; Leif Göransson - leif.goransson@lantmannen.se; Staffan Lindeberg - staffan.lindeberg@med.lu.se

* Corresponding author
\end{abstract}

Published: 02 November 2006

Received: 17 July 2006

Nutrition \& Metabolism 2006, 3:39 doi:10.1 186/1743-7075-3-39

Accepted: 02 November 2006

This article is available from: http://www.nutritionandmetabolism.com/content/3/I/39

(c) 2006 Jönsson et al; licensee BioMed Central Ltd.

This is an Open Access article distributed under the terms of the Creative Commons Attribution License (http://creativecommons.org/licenses/by/2.0), which permits unrestricted use, distribution, and reproduction in any medium, provided the original work is properly cited.

\begin{abstract}
Background: A Paleolithic diet has been suggested to be more in concordance with human evolutionary legacy than a cereal based diet. This might explain the lower incidence among hunter-gatherers of diseases of affluence such as type 2 diabetes, obesity and cardiovascular disease. The aim of this study was to experimentally study the long-term effect of a Paleolithic diet on risk factors for these diseases in domestic pigs. We examined glucose tolerance, post-challenge insulin response, plasma C-reactive protein and blood pressure after 15 months on Paleolithic diet in comparison with a cereal based swine feed.
\end{abstract}

Methods: Upon weaning twenty-four piglets were randomly allocated either to cereal based swine feed (Cereal group) or cereal free Paleolithic diet consisting of vegetables, fruit, meat and a small amount of tubers (Paleolithic group). At 17 months of age an intravenous glucose tolerance test was performed and pancreas specimens were collected for immunohistochemistry. Group comparisons of continuous variables were made by use of the t-test. $P<0.05$ was chosen for statistical significance. Simple and multivariate correlations were evaluated by use of linear regression analysis.

Results: At the end of the study the Paleolithic group weighed $22 \%$ less and had $43 \%$ lower subcutaneous fat thickness at mid sternum. No significant difference was seen in fasting glucose between groups. Dynamic insulin sensitivity was significantly higher $(p=0.004)$ and the insulin response was significantly lower in the Paleolithic group $(p=0.00 \mathrm{I})$. The geometric mean of $C$-reactive protein was $82 \%$ lower $(p=0.0007)$ and intra-arterial diastolic blood pressure was $13 \%$ lower in the Paleolithic group $(p=0.007)$. In evaluations of multivariate correlations, diet emerged as the strongest explanatory variable for the variations in dynamic insulin sensitivity, insulin response, C-reactive protein and diastolic blood pressure when compared to other relevant variables such as weight and subcutaneous fat thickness at mid sternum. There was no obvious immunohistochemical difference in pancreatic islets between the groups, but leukocytes were clearly more frequent in sampled pancreas from the Cereal group.

Conclusion: This study in domestic pigs suggests that a Paleolithic diet conferred higher insulin sensitivity, lower C-reactive protein and lower blood pressure when compared to a cereal based diet. 


\section{Background}

Our pre-agricultural, hunter-gatherer human ancestors during the Paleolithic period (the old stone age; 2.5 million - 10,000 years BP) had a diet based on vegetables, fruit, nuts, roots, meat, organ meats and insects [1]. This Paleolithic diet has been suggested to be more in concordance with our evolutionary legacy than a diet based on products associated with agriculture during the Neolithic period (10,000 years BP - present time) such as cereals and milk [2,3]. A diet in less concordance with our evolutionary legacy might confer diseases due to insufficient adaptation [4] possibly explaining the reported lower incidence of diseases of affluence [5], such as type 2 diabetes, obesity and cardiovascular disease among NonWestern ethnic groups with hunter-gatherer lifestyles and diets [6,7]. However, the mechanisms behind this reported lower incidence of diseases of affluence are largely unknown, and commonly discussed dietary factors such as fat (amount and quality) and (cereal) fiber may be of limited importance [8-10]. A possible mechanism might be the potential of Paleolithic diet to reduce risk factors for diseases of affluence, such as disturbed glucose homeostasis, insulin resistance and hypertension [2]. Food restriction induced by the satiating properties of a Paleolithic diet [2] may also play a role. Food restriction, sometimes referred to as dietary restriction or caloric restriction [11], of 20-40\% of dietary energy compared to free feeding (ad libitum) has been shown to reduce the incidence of several diseases of affluence in mammals including non-human primates, and possibly humans $[12,13]$. Interestingly, Non-Western ethnic groups with hunter-gatherer lifestyles and diets stay lean and apparently reap health benefits similar to those induced by food restriction despite ad libitum availability of food [14].

The aim of this study was to determine experimentally whether a Paleolithic diet on a long-term basis affects risk factors for diseases of affluence in a prospective and randomized setting. This was assessed in domestic swine by examining glucose tolerance, post-challenge insulin response, plasma C-reactive protein and blood pressure after 15 months on a Paleolithic diet in comparison with a cereal based swine feed supplemented with rapeseed oil.

\section{Methods}

\section{Animals and diet}

The animals in this study received humane care in compliance with the "Principles of Laboratory Animal Care" formulated by the National Society for Medical Research and the "Guide for the Care and Use of Laboratory Animals" (National Institutes of Health publication 85-23, revised 1985). The Ethical Committee for Animal Experiments at Lund University approved the study (diary number $M$ 263-02). Twenty-four cross-bred (dam (Swedish Landrace $\times$ Yorkshire $) \times$ sire Hampshire) piglets from four different litters were eligible for the study. Upon weaning, the piglets were randomly allocated either to a group fed a standard cereal based swine feed (hereafter referred to as Cereal group) supplemented with rapeseed oil in order to match fat intake in the two groups, or to a group fed a cereal free Paleolithic diet (hereafter referred to as Paleolithic group) consisting of vegetables, fruit, meat and a small amount of tubers. At baseline body weight did not differ between the groups $(28.9 \pm 2.9 \mathrm{~kg}$ vs. $30.7 \pm 2.8 \mathrm{~kg}$, Paleolithic vs. Cereal group, $\mathrm{p}=0.2)$. In the Paleolithic group one pig, an apparent runt, failed to thrive from early post weaning and was culled at 3.5 months of age. Inclusion of meat (beef) was approved by the Swedish Board of Agriculture. Average intake during the study of protein, fat and carbohydrates were $17 \%, 18 \%$ and $65 \%$ respectively in the Cereal group, and 27\%, 16\% and 57\% respectively in the Paleolithic group. Both diets were thus high in carbohydrate and low in fat compared to the spectrum of macronutrient intake estimated for contemporary huntergatherers [1]. For more detailed account of provisions during the last three months of the study, see Table 1 . Both groups were fed their respective diet from 2 to 17 months of age by an experienced experimental pig farmer who allocated rations on a group basis judged sufficient to achieve healthy animals. Body weight was recorded every second week.

\section{Anaesthesia}

At age 17 months all animals received premedication in the stable with intramuscular ketamine (Ketalar, ParkeDavis, Morris Plains, NJ), $7.5 \mathrm{mg} / \mathrm{kg}$ body weight and xylasin (Rompun, Bayer, Gothenburg, Sweden) 0.125 $\mathrm{mg} / \mathrm{kg}$. When sedated an intravenous needle was inserted in an ear vein and thiopental (Pentothal, Abbot, North Chicago, Il) $0.5 \mathrm{mg} / \mathrm{kg}$ and atropine (Atropine, Kabi Pharmacia, Uppsala, Sweden) $0.02 \mathrm{mg} / \mathrm{kg}$ were given. During the experiment, anesthesia was maintained using propofol (Diprivan, AstraZeneca, Södertälje, Sweden) 9-15 mg/ $\mathrm{kg} / \mathrm{h}$. Fentanyl (Leptanal, Janssen-Cilag, Sollentuna, Sweden) $0.02 \mu \mathrm{g} / \mathrm{kg}$ and atracurium (Tracrium, Epipharm, Gnesta, Sweden) $0.2-0.5 \mathrm{mg} / \mathrm{kg}$ were given intermittently for pain management and muscular relaxation, respectively. The animals were ventilated with a Siemens Servo ventilator 300 (Siemens-Elema AB, Solna, Sweden). A volume-controlled, pressure-regulated ventilation of 14-20 $\mathrm{L} / \mathrm{min}$ (15 breaths/min; positive end-expiratory pressure [PEEP], $5 \mathrm{~cm} \mathrm{H} 2 \mathrm{O}$; inspired oxygen fraction, 0.5; $\max$ inspiratory pressure, $30 \mathrm{~cm} \mathrm{H}_{2} \mathrm{O}$ ) was used.

\section{Experimental protocol}

An intravenous glucose tolerance test (IVGTT) was performed in 20 pigs which had been fasted for at least 6 hours. The pigs were kept in a supine position during the IVGTT, and hemodynamic values and body temperature (measured by naso-pharyngeal probe) were recorded 
Table I: Provisions during last three months in study

\begin{tabular}{|c|c|c|}
\hline Paleolithic group & kg/pig/day & kJ/pig/day \\
\hline Cabbage & I & 915 \\
\hline Turnip & I & 703 \\
\hline Cauliflower & 0.7 & 661 \\
\hline Green pepper & 0.05 & 34 \\
\hline Red pepper & 0.05 & 55 \\
\hline Yellow pepper & 0.05 & 47 \\
\hline Broccoli & 0.15 & 179 \\
\hline Apple & I & 2053 \\
\hline Pear & 0.7 & 1286 \\
\hline Kiwi fruit & 0.1 & 192 \\
\hline Water melon & 0.1 & 149 \\
\hline Grape & 0.03 & 88 \\
\hline Pineapple & 0.03 & 60 \\
\hline Cherimoya & 0.03 & 115 \\
\hline Potato & 0.3 & 878 \\
\hline Carrot & 0.3 & 474 \\
\hline Beetroot & 0.1 & 160 \\
\hline Parsnip & 0.05 & 106 \\
\hline Black radish & 0.05 & 29 \\
\hline Beef & 0.45 & 2995 \\
\hline Fish-meal & 0.36 & 5882 \\
\hline Total & 6.6 & 17063 \\
\hline Cereal group & kg/pig/day & kJ/pig/day \\
\hline Cereal swine feed & 1.5 & 18600 \\
\hline Rape-seed oil & 0.06 & 2220 \\
\hline Total & 1.56 & 20820 \\
\hline
\end{tabular}

Energy intake at the end of the study was approximately $20 \%$ lower in the Paleolithic group as compared to the Cereal group despite much larger feed rations in terms of both volume and weight.

using a data acquisition system (Testpoint; Capital Equipment Corp, Billerica, MA). A catheter was introduced into the external jugular vein and threaded into the superior vena cava for both glucose administration and blood sampling. At -5 min and -30 seconds before glucose administration, 2.5-ml blood samples were collected. At time 0 , glucose $(0.5 \mathrm{~g} / \mathrm{kg}$ body weight) was infused over $20-30$ seconds. Thereafter, $2.5 \mathrm{ml}$ blood samples were drawn at $2,3,4,5,6,8,10,12,14,16,18,19,22,25,30,35,40$, $45,50,55,60,75,90,105$ and $120 \mathrm{~min}$. An equivalent amount of sterile saline solution was used to flush the catheter line. The tubes were centrifuged, and plasma was stored at $-20^{\circ} \mathrm{C}$ for analysis of insulin and glucose concentrations using standard methods. Body length was measured from nose to end of buttocks. Subcutaneous fat thickness was measured with a ruler at mid sternum after the thorax was opened. For immunohistochemistry of islet hormones and islet morphology, specimens were collected from mid-and tail portions of the pancreas from 5 pigs in each group. Two specimens were collected from each site. One specimen was fixed overnight in buffered formaldehyde $(4 \%)$, dehydrated in graded ethanols, and embedded in paraffin. The other specimen was fixed in Stefanini's solution (2\% paraformaldehyde and $0.2 \%$ picric acid in $0.1 \mathrm{M}$ phosphate buffer, $\mathrm{pH} 7.2$ ), rinsed thoroughly in Tyrode solution containing $10 \%$ sucrose, and frozen on dry ice. Sections from paraffin-embedded specimens, and cryosections were then processed for indirect immunofluorescence using well characterised islet hormone antisera as primary antibodies, and FITClabelled second antibodies. For details on the antibodies used, and the immunostaining protocol, see e.g. Wierup et al 2002 [15].

\section{Data analysis and statistics}

Continuous variables showed near Normal distribution in Normal plots (not shown), but in the case of C-reactive protein only after logarithmic transformation. Two pigs, one in each group, were obvious outliers given the extremely elevated insulin response to injected glucose (insulin area under the curve (AUC) 12 and 11 standard deviations above the group mean). These were excluded from calculations regarding glucose and insulin (basal and dynamic variables) and their respective correlations with other variables. Plasma glucose in remaining animals decreased exponentially (adjusted $\mathrm{R}^{2}=0.93$ and 0.92 in the Paleolithic and Cereal group, respectively; $\mathrm{p}=$ $0.0001)$. Therefore, the glucose tolerance index $K_{G}$ could be calculated as the regression slope of the logarithmic transformation of glucose concentration versus time from $8 \mathrm{~min}$, when problems related to glucose mixing are over. In contrast to glucose, which returned to values similar to pre-injection levels by $90 \mathrm{~min}$ (Figure 2), insulin remained elevated at 2 hours (Figure 3 ), precluding the use of the minimal model of glucose disappearance to estimate insulin sensitivity $[16,17]$. Fasting insulin sensitivity, which mostly accounts for the processes in the liver [18], was calculated with the QUICKI index [19]. For the dynamic part of the IVGTT, a surrogate of insulin sensitivity was calculated as glucose disappearance rate (expressed by $\mathrm{K}_{\mathrm{G}}$ ) divided by the prevailing insulin (expressed by insulin AUC from 0 to 120 min (AUCins $_{0-}$ $120)$ ). Dynamic insulin sensitivity accounts for the insulin action at the level of muscle and adipose tissues [18]. Insulin secretion was evaluated as the suprabasal AUCins $_{0-120}$, representing the glucose stimulated insulin response. Finally, acute insulin response was calculated as the average insulin concentration during the very early phase ( 2 to $4 \mathrm{~min}$ ) after glucose injection. AUC was calculated with the trapezoidal rule. Data and results are expressed as mean \pm standard deviation. Group comparisons of continuous variables were made by use of the unpaired two-sided Student's t-test with equal variances assumed. $\mathrm{P}<0.05$ was chosen for statistical significance. Bivariate correlations were evaluated by simple linear 
regression analyses, while multivariate correlations were evaluated by forward stepwise linear regression analyses. Due to the small sample size in this study only two variables were entered as independent variables in each regression model when analysing multivariate correlations, and even then the correlations should be interpreted with caution.

\section{Results}

Energy intake at age 17 months was approximately $20 \%$ lower in the Paleolithic group despite much larger feed rations in terms of both volume and weight (Table 1 ). The mean weight curves for the two groups started to diverge after 3 months of feeding the different diets (Figure 1). At the end of the study the Paleolithic group weighed 22\% less $(129 \pm 16 \mathrm{~kg}$ vs. $166 \pm 28 \mathrm{~kg}$, Paleolithic vs. Cereal, p $=0.0009$; Table 2 and insert Figure 1) and was 6\% shorter than the Cereal group ( $\mathrm{p}=0.003)$, while subcutaneous fat thickness was $43 \%$ lower $(\mathrm{p}=0.0003$; Table 2$)$. No significant difference was seen in body temperature between groups (Table 2 ). The geometric mean of $\mathrm{C}$-reactive protein was $82 \%$ lower in the Paleolithic group $(\mathrm{p}=0.0007$; Table 2). Intra-arterial diastolic blood pressure was significantly lower by $13 \%(\mathrm{p}=0.007)$ in the Paleolithic group, while systolic blood pressure was non-significantly lower by $7 \%(\mathrm{p}=0.12$; Table 2$)$.

No significant difference was seen in mean fasting values of glucose or insulin between the groups (Table 3). Parameters related to the overall metabolic status indicated unchanged total glucose AUC ( $\mathrm{p}=0.14$; Table 3, Figure 2$)$ and glucose disappearance rate $\left(\mathrm{K}_{\mathrm{G}}=0.58 \pm 0.12 \mathrm{vs}\right.$. $0.67 \pm 0.17 \% \mathrm{~min}^{-1}$, Paleolithic vs. Cereal, $\mathrm{p}=0.20$; Table 3). Fasting insulin sensitivity was not affected by diet (QUICKI $=0.66 \pm 0.15$ vs. $0.70 \pm 0.36$, Paleolithic vs. Cereal, $\mathrm{p}=0.7$; Table 3 ), but dynamic insulin sensitivity was markedly higher in the Paleolithic group (dynamic insulin sensitivity $=2.35 \pm 0.76$ vs. $1.41 \pm 0.39 \% \mathrm{~min}^{-1} /$ (pmol/l), Paleolithic vs. control, $\mathrm{p}=0.004$; Table 3). Significant differences were also found in the insulin response to injected glucose (Table 3, Figure 3). AUCins ${ }_{0-}$ ${ }_{120}$ was significantly lower in the Paleolithic group by $47 \%$ $(\mathrm{p}=0.001)$ and stimulated insulin secretion was even more reduced by $58 \%(\mathrm{p}=0.0005)$. This reduction was mostly ascribed to the second phase insulin secretion, since the acute insulin response immediately following the glucose bolus (indicator of the early phase insulin release) was not different between the two groups (14.9 \pm

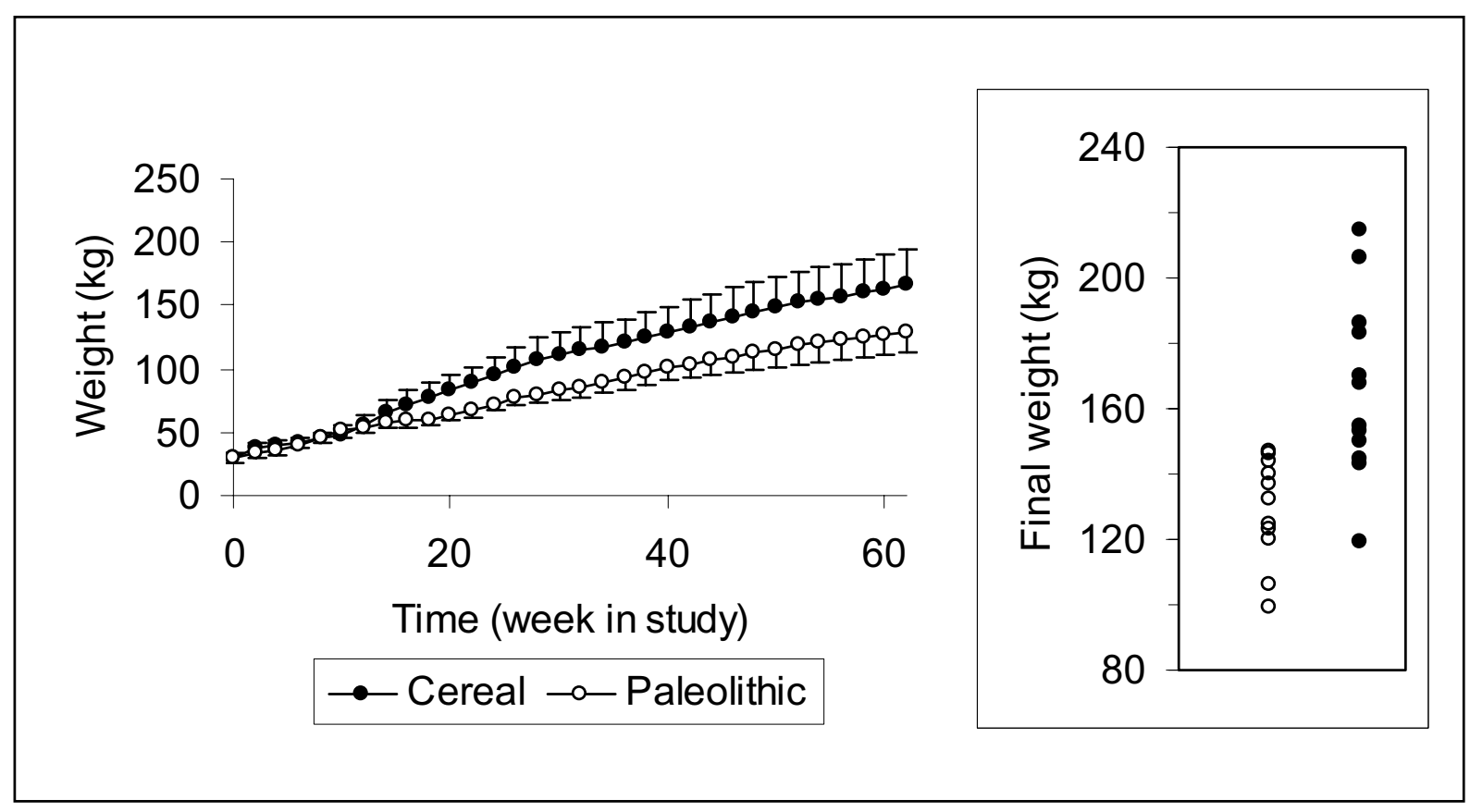

Figure I

Average weight during study and final weight. The curves representing mean group weight started to diverge after 3 months of feeding the different diets. Spread of individual weights at the end of the study displayed some overlap between groups (insert). 


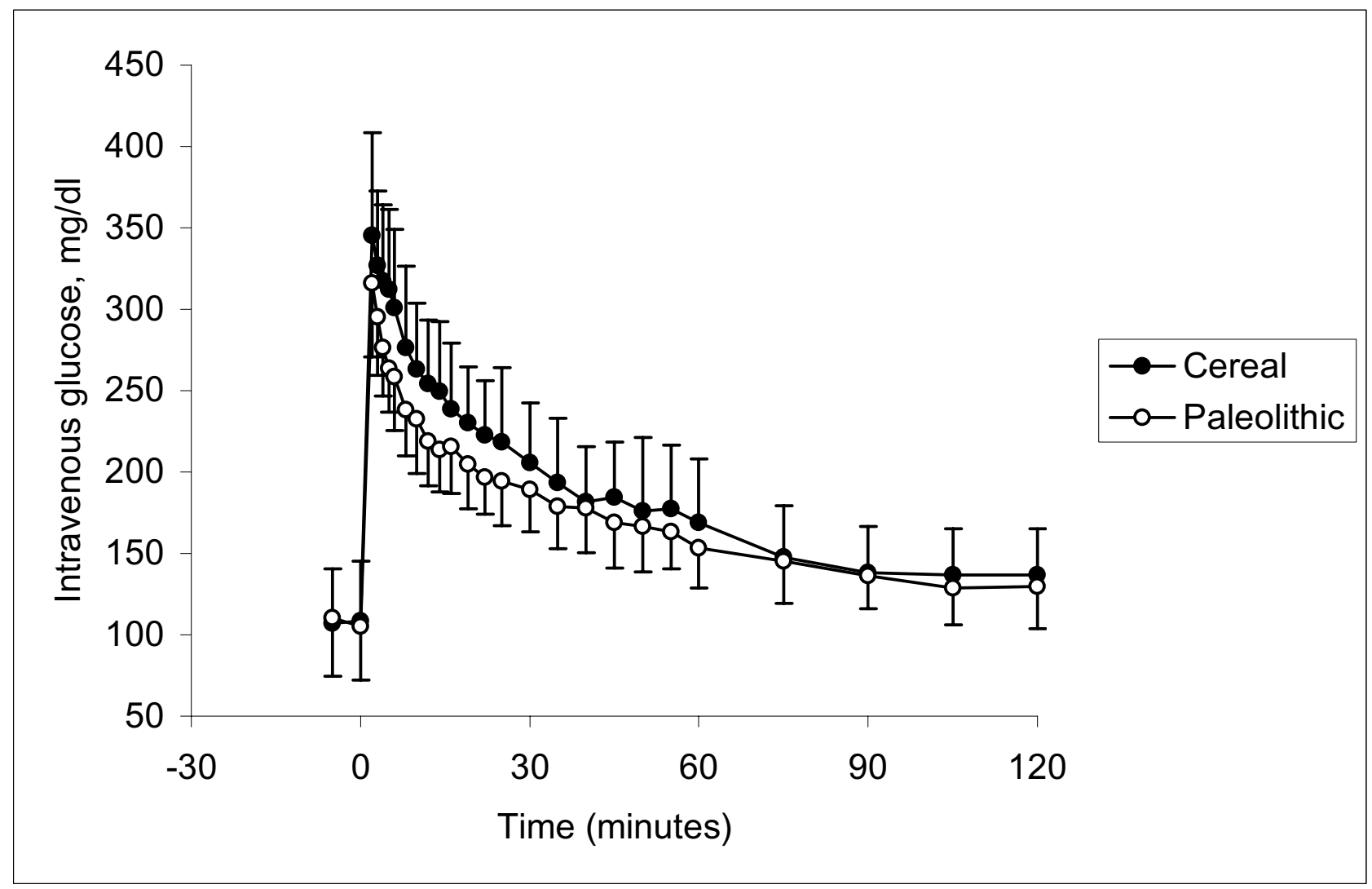

Figure 2

Glucose response during glucose tolerance test. No significant difference was observed between groups in average glucose response after an intravenous bolus of glucose $(0.5 \mathrm{~g} / \mathrm{kg}$ body weight $)$ at age 17 months.

8.3 vs. $15.8 \pm 10.7 \mathrm{pmol} / \mathrm{l}, \mathrm{p}=0.8$, Paleolithic vs. control; Table 3).

Evaluations of bivariate correlation showed that weight was highly correlated with subcutaneous fat thickness (adjusted R2 $=0.77, \mathrm{p}<0.0001$ ). Evaluations of multivariate correlation with forward stepwise linear regression analysis was performed in order to study variables independently explaining the variation of dynamic insulin sensitivity, AUCins ${ }_{0-120}, \log$ C-reactive protein and diastolic blood pressure, respectively. In each of these four regression models diet was entered as independent variable and evaluated with each one of the remaining relevant study variables as the second independent variable. Diet emerged as the strongest explanatory variable for variations in dynamic insulin sensitivity, AUCins ${ }_{0-120}, \log \mathrm{C}-$ reactive protein and diastolic blood pressure.

Immunohistochemical analysis comprised islet staining of insulin, glucagon, somatostatin and pancreatic polypeptide. There was no obvious difference between islets in the Cereal and Paleolithic groups regarding the frequencies or intra-islet distribution patterns of cells storing each of these four hormones, nor was the islet size or islet frequency overtly different (Figure 4). However, leukocytes, as revealed by their unspecific binding of the secondary antibodies, their small size, and their characteristic nuclei, were clearly more frequent (more than doubled by simple cell counting) in all the sampled pigs from the Cereal group as compared to all the sampled pigs from the Paleolithic group, with no overlapping between groups. These cells usually occurred scattered throughout the exocrine pancreatic parenchyma or clustered around pancreatic ducts and blood vessels (Figure 5).

\section{Discussion}

This study showed highly beneficial effects of a Paleolithic diet on risk factors for diseases of affluence when compared to cereal based swine feed. A strength of the study is that the model used is one of the best non-primate models for human disorders, the domestic pig [20]. The present study indicated no difference in glucose disap- 


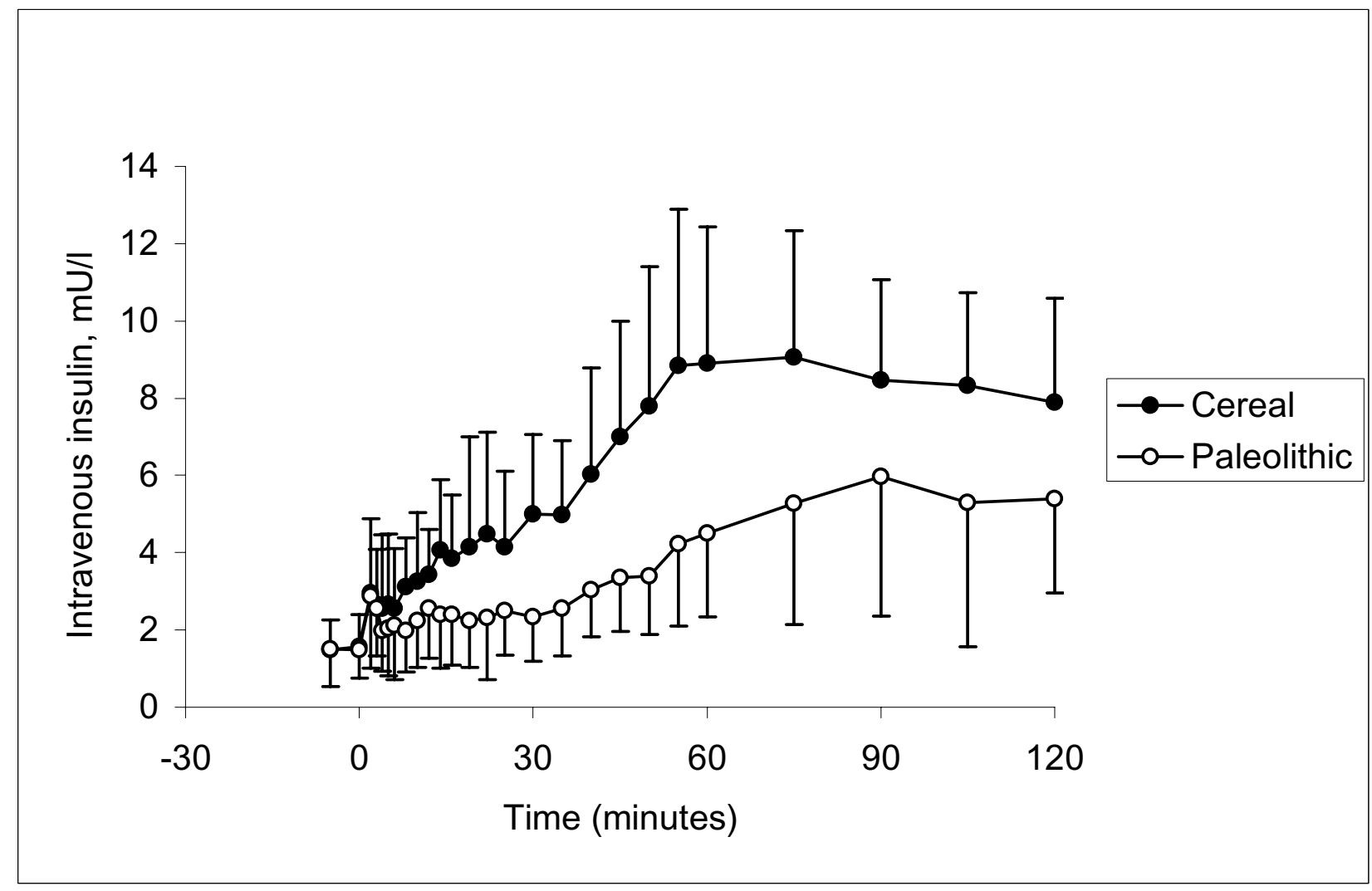

Figure 3

Insulin response during glucose tolerance test. Average insulin area under the curve from 0 to 120 minutes was significantly lower by $47 \%$ in the Paleolithic group as compared to the Cereal group after an intravenous bolus of glucose $(0.5 \mathrm{~g} / \mathrm{kg}$ body weight) at age 17 months $(p=0.001)$.

pearance during IVGTT between the groups. During IVGTT plasma insulin increased successively between 30 and $80 \mathrm{~min}$ in both groups, possibly due to propofol anesthesia $[21,22]$, and this precluded the use of the minimal model of glucose disappearance $[16,17]$. However, other indices of dynamic insulin sensitivity clearly showed higher insulin sensitivity in the Paleolithic group, which also exhibited a significantly lower insulin response to injected glucose. It is worth noting that the difference in insulin response between groups during IVGTT was observed in the late phase of insulin secretion. Evaluation of multivariate correlation showed that the beneficial effect of Paleolithic diet on insulin sensitivity and insulin response was independent of all other relevant study variables such as body weight, subcutaneous fat thickness and body temperature. A Paleolithic diet thus conferred higher insulin sensitivity, which is central to the prevention of cardiovascular disorders [23], and consistent with our finding in humans [24]. Furthermore, contrary to our survey in humans [24], this finding of higher insulin sensitivity was associated with no significant difference between groups in fasting levels of insulin and glucose, indicating that the Paleolithic diet affected insulin action mainly at the level of muscle and adipose tissues rather than the liver [18].

The Paleolithic group also showed significantly lower levels of C-reactive protein, a physiologic marker of subclinical inflammation, which has been shown to be associated with insulin resistance and cardiovascular disease [23,25]. Elevated levels of C-reactive protein has been suggested to reflect overproduction by expanded adipose tissue mass [23]. However, evaluation of multivariate correlation showed that the beneficial effect of Paleolithic diet on Creactive protein was independent of all other relevant study variables including measures of obesity such as body weight and subcutaneous fat thickness. Interestingly, immunohistochemical analysis suggested a diffuse and low-grade pancreatic inflammation in the cereal group, as evidenced by clearly more frequent leukocytes 
Table 2: Final clinical characteristics (mean \pm standard deviation)

\begin{tabular}{lccc}
\hline & Paleolithic group $(\mathrm{n}=\mathrm{II})$ & Cereal group $(\mathrm{n}=\mathrm{I})$ \\
\hline Weight $(\mathrm{kg})$ & $129 \pm 16$ & $166 \pm 28$ \\
Length $(\mathrm{cm})$ & $159 \pm 6$ & $170 \pm 9$ & 0.0009 \\
Subcutaneous fat $(\mathrm{cm})$ & $1.9 \pm 0.4$ & $3.3 \pm 0.9$ & $37.6 \pm 0.5$ \\
Body temperature $\left({ }^{\circ} \mathrm{C}\right)$ & $37.7 \pm 1.5$ & 21.7 & 0.0003 \\
CRP $(\mu \mathrm{gg} / \mathrm{mL}) 1$ & 4.0 & $150 \pm 9$ & 0.8 \\
Systolic Blood Pressure $(\mathrm{mm} \mathrm{Hg})$ & $140 \pm 18$ & $123 \pm 12$ & 0.12 \\
Diastolic Blood Pressure $(\mathrm{mm} \mathrm{Hg})$ & $108 \pm 12$ & 0.007
\end{tabular}

I geometric mean, t-test on logarithmic CRP. Final clinical characteristics in pigs fed paleolithic or cereal diet from 2 to I7 months of age.

scattered throughout their exocrine pancreatic parenchyma or clustered around pancreatic ducts and blood vessels. This finding offers a novel approach in the research on the association between inflammation and type 2 diabetes [25]. Immunohistochemical analysis also showed that the cereal group could compensate for both pancreatic inflammation and increased need of insulin due to lower insulin sensitivity, without noticeable differences in pancreatic islets between groups.

The shorter length in the Paleolithic group is not unexpected if we consider length in pigs as a correlate of height in humans. Available evidence suggests that hunter-gatherers and similar ethnic groups are shorter than Western populations, and a positive relationship between height and cardiovascular disease has been noted in international comparisons [26]. Insulin resistance and hyperinsulinemia can hypothetically promote growth by way of insulin-like growth factors [27].

In addition to these significant results, intra-arterial diastolic blood pressure was significantly lower in the Paleolithic group, and this beneficial effect of Paleolithic diet was also independent of all other relevant study variables. The present study thus provides experimental evidence for beneficial effects of a Paleolithic diet on risk factors for diseases of affluence, which might account for their low incidence reported among Non-Western ethnic groups with hunter-gatherer lifestyles and diets [6,7].

\section{Effecting mechanisms}

The mechanisms behind these beneficial effects on risk factors are largely unknown. In evaluations of multivariate correlation, diet emerged as a stronger explanatory variable than any other relevant variable for variations in dynamic insulin sensitivity, AUCins ${ }_{0-120}$, log C-reactive protein and diastolic blood pressure. The observed effects on risk factors thus seem to be primarily caused by diet. However, it is conceivable that this dietary effect on risk factors is a result of differences in other variables induced by dietary assignment. An important finding in this regard is the divergence of the weight curves between the two groups after 3 months of feeding. The Paleolithic group was thus lighter and had a lower energy intake at the end of the study than the Cereal group, despite a threefold larger ration by weight. The diverging weight curves could be interpreted in several ways. They could be interpreted as food restriction in the Paleolithic group, which could explain the observed effects on risk factors [28]. Neither group was fed their respective diet ad libitum but was rather allocated rations on a group basis judged sufficient to achieve healthy animals by an experienced experimental pig farmer. This procedure was chosen due to concerns about the unfamiliar Paleolithic diet as swine feed, and the fact that feeding ad libitum is not the custom in Swed-

Table 3: Final glucometabolic characteristics (mean \pm standard deviation)

\begin{tabular}{|c|c|c|c|}
\hline & Paleolithic group $(n=9)$ & Cereal group $(n=9)$ & $P$ \\
\hline fP-glucose (mmol/l) & $5.6 \pm 1.4$ & $6.0 \pm 1.9$ & 0.6 \\
\hline AUC' glucose $0-120 \mathrm{~min}(\mathrm{mmol} / / \mathrm{min})$ & $1076 \pm 113$ & $1199 \pm 212$ & 0.14 \\
\hline $\mathrm{K}_{\mathrm{G}}(\% \min -1)$ & $0.58 \pm 0.12$ & $0.67 \pm 0.17$ & 0.20 \\
\hline fP-insulin $(\mathrm{mmol} / \mathrm{l})$ & $8.3 \pm 4.6$ & $9.2 \pm 4.6$ & 0.7 \\
\hline QUICKI & $0.66 \pm 0.15$ & $0.70 \pm 0.36$ & 0.7 \\
\hline Dynamic insulin sensitivity (\%min-l/(pmol/l)) & $2.35 \pm 0.76$ & $\mathrm{I} .4 \mathrm{I} \pm 0.39$ & 0.004 \\
\hline AUCI insulin $0-120 \mathrm{~min}(\mathrm{pmol} / \mathrm{l} \mathrm{min})$ & $2613 \pm 863$ & $4973 \pm 1476$ & 0.001 \\
\hline AUC' insulin 0-120 min stimulated secretion ( $\mathrm{pmol} / / \mathrm{min})$ & $1620 \pm 1074$ & $3872 \pm 1112$ & 0.0005 \\
\hline Acute insulin response $2-4 \mathrm{~min}(\mathrm{pmol} / \mathrm{l})$ & $14.9 \pm 8.3$ & $15.8 \pm 10.7$ & 0.8 \\
\hline
\end{tabular}

Iarea under curve during intravenous glucose tolerance test. Final glucometabolic characteristics in pigs fed paleolithic or cereal diet from 2 to 17 months of age excluding cases fasting less than 6 hours. 

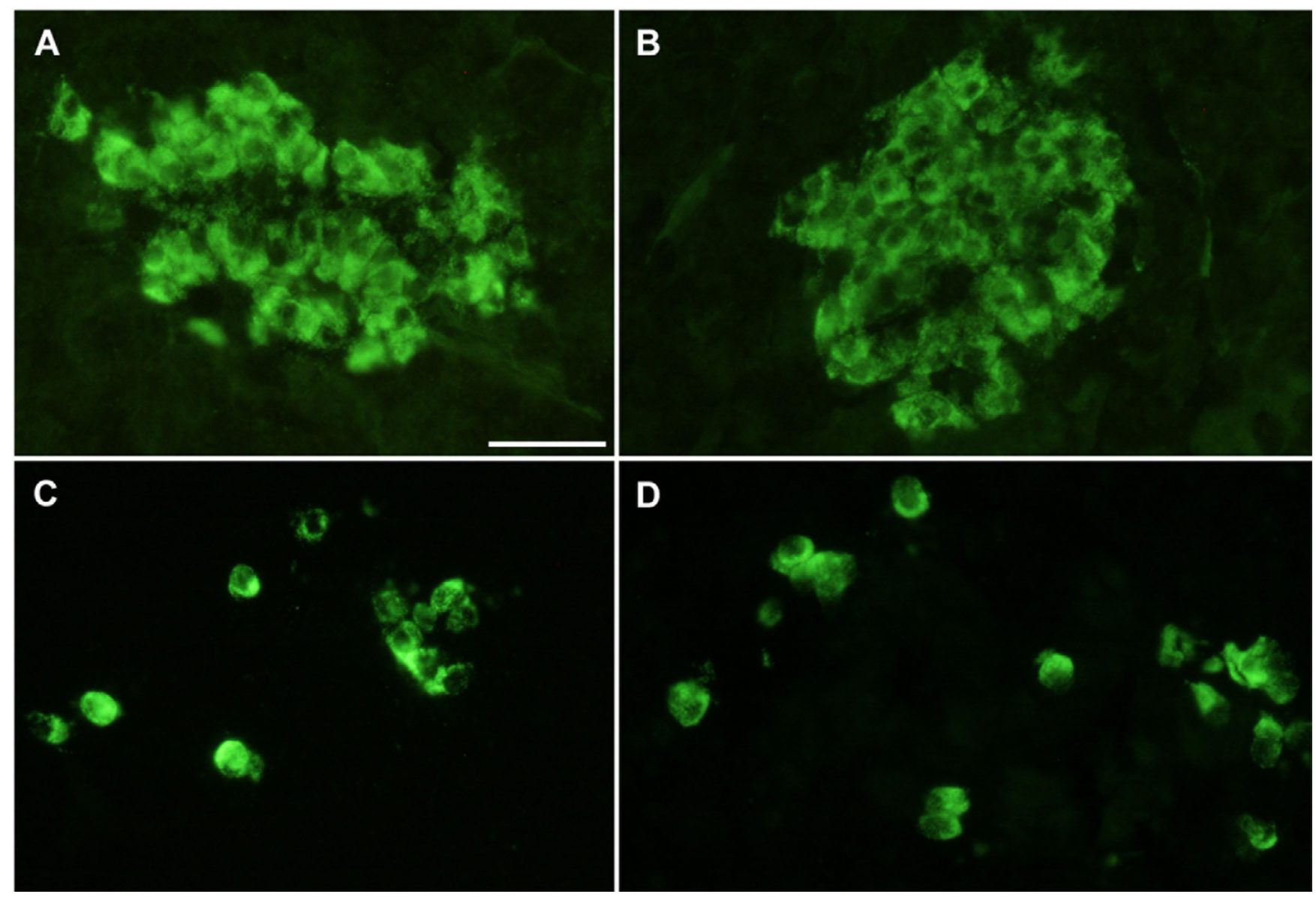

\section{Figure 4}

Immunohistochemical staining of pancreatic islets. Immunohistochemical staining of pancreatic islets showed no obvious difference between Cereal $(A$ and $C)$ and Paleolithic ( $B$ and $D)$ groups regarding the frequencies or intraislet distribution patterns of cells storing insulin ( $A$ and $B)$, glucagon $(C$ and $D)$, somatostatin and pancreatic polypeptide, nor was the islet size or islet frequency overtly different.

ish swine production. The diverging weight curves between the groups could thus possibly be caused by differences in subjectively allocated rations (e.g. difference in energy intake), which could lead to food restriction in the Paleolithic group. However, food restriction typically lowers mean body temperature by $1-2^{\circ} \mathrm{C}[29]$, and we found no significant difference in mean body temperature between the two groups, indicating that there was not a substantial food restriction in the Paleolithic group as compared to the Cereal group. In fact, the mean weight in the Paleolithic group is well within the normal range of pigs [30]. The diverging weight curves are thus probably not caused by food restriction in the Paleolithic group but instead could be interpreted as obesity in the Cereal group in analogy with human classification of individual weight based on statistical health effects [31]. The significant difference in subcutaneous fat thickness between groups and the high correlation between weight and subcutaneous fat thickness supports this notion. Obesity in humans is asso- ciated with increased insulin resistance, high blood pressure and high levels of C-reactive protein [23], and could explain the observed effects on risk factors. The difference between the two diets regarding obesity promotion could still be due to differences in subjectively allocated rations, but could alternatively be due to properties of a cereal based swine feed which possibly disturb the regulation of satiation [3], satiating properties of a Paleolithic diet [2] and differing effects between the diets on energy metabolism [2]. The satiating properties of a Paleolithic diet could be due to differences in macronutrient diet composition, such as the low protein content of cereals in the Cereal group diet. The Paleolithic group thus ate relatively more protein and less carbohydrates, which through satiating, thermogenic and other properties could account for the results of the study [32,33], although results from studies on the association between protein intake and diseases of affluence have been contradictory [34]. In future studies of Paleolithic diets it would be valuable to match 

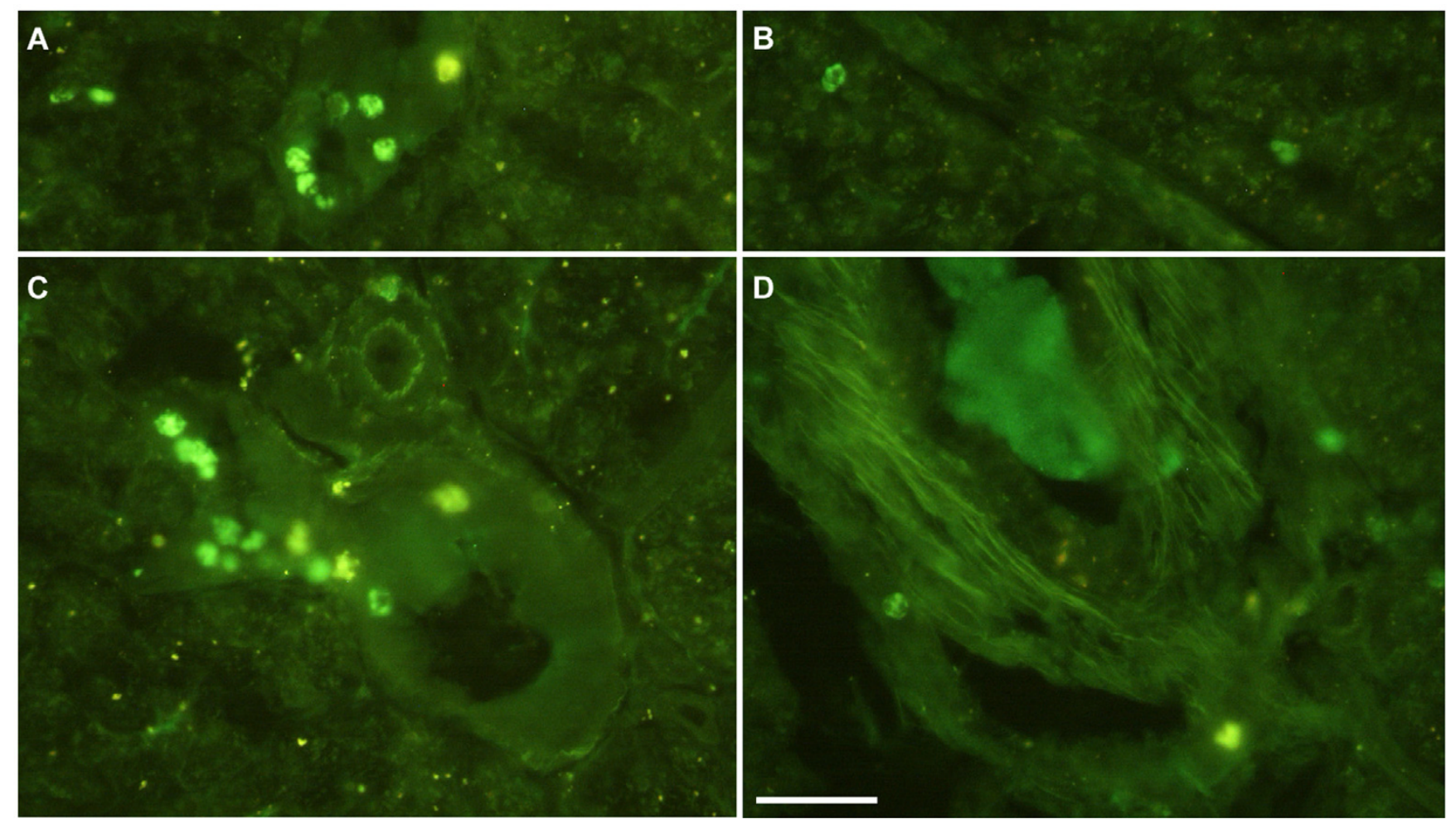

\section{Figure 5}

Frequency of pancreatic leukocytes. Leukocytes, as revealed by their unspecific binding of the secondary antibodies, their small size, and their characteristic nuclei, were clearly more frequent (more than doubled by cell counting) in all the sampled pigs from the Cereal group ( $A$ and $C, n=5)$ as compared to all the sampled pigs from the Paleolithic group $(B$ and $D, n=5)$, with no overlapping between groups. These cells usually occurred scattered throughout the exocrine pancreatic parenchyma or clustered around pancreatic ducts (A and $B)$ and blood vessels (C and D).

diets for macronutrient composition. The latter alternative explanations for the diverging weight curves is supported by our epidemiological findings in humans from Kitava, Papua New Guinea, where a non-western lifestyle has been connected to leanness despite food being available ad libitum [13]. The diverging weight curves would then suggest that the beneficial effects on risk factors could be due to differences between diets regarding obesity promotion. Alternatively, obesity could be a marker for other effecting mechanisms, such as leptin resistance, and the diverging weight curves would then suggest that the beneficial effects on risk factors could be due to differences between diets regarding promotion of leptin resistance [3].

\section{Conclusion}

In conclusion, this study in domestic pigs suggests that a Paleolithic diet as compared to a cereal based diet conferred higher insulin sensitivity, lower C-reactive protein and lower blood pressure. The results suggest that pigs, as previously suggested for humans [3], are not specifically adapted through evolution to a diet incorporating large amounts of cereals, which could confer diseases of affluence as a sign of insufficient evolutionary adaptation [4].

\section{Competing interests}

The author(s) declare that they have no competing interests.

\section{Authors' contributions}

TJ participated in the design of the study and in carrying out the experiments at the end of the study, participated in statistical analysis, and conceived of and wrote the article. BA participated in the design of the study, carried out the analysis of glucose and insulin, and conceived of and participated in the design of the article as well as revising it for important intellectual content. GP participated in the statistical analysis of glucose and insulin and revised the article for important intellectual content. FS and NW participated in carrying out the experiments at the end of the study, and carried out the immunohistochemical studies. SS and TS participated in the overall design and coordination of the study, were responsible for the animals and the laboratory where the experiment was per- 
formed, and participated in carrying out the experiments at the end of the study. MU participated in carrying out the experiments at the end of the study and revised the article for important intellectual content. JF carried out the analysis on C-reactive protein and revised the article for important intellectual content. LG revised the article for important intellectual content. SL conceived of and participated in the design, coordination and execution of the study, participated in carrying out the experiments at the end of the study, participated in statistical analysis, conceived of and participated in the design of the article as well as revising it for important intellectual content. All authors read and approved the final manuscript.

\section{Acknowledgements}

The authors are grateful to Lilian Bengtsson, Jun Su and Doris Persson for technical assistance. The study was supported by grants from the Swedish Research Council (6834 and 4499), Swedish Diabetes Association, Albert Påhlsson Foundation, Novo Nordic Foundation, Region Skåne and the Faculty of Medicine, Lund University.

\section{References}

I. Cordain L, Miller JB, Eaton SB, Mann N, Holt SH, Speth JD: Plant-animal subsistence ratios and macronutrient energy estimations in worldwide hunter-gatherer diets. Am J Clin Nutr 2000, 71:682-692.

2. Cordain L, Eaton SB, Sebastian A, Mann N, Lindeberg S, Watkins BA, $\mathrm{O}$ 'Keefe $\mathrm{JH}$, Brand-Miller J: Origins and evolution of the Western diet: health implications for the 2 Ist century. Am J Clin Nutr 2005, 8I:34I-354.

3. Jonsson T, Olsson S, Ahren B, Bog-Hansen TC, Dole A, Lindeberg S: Agrarian diet and diseases of affluence - Do evolutionary novel dietary lectins cause leptin resistance? BMC Endocr Disord 2005, 5: 10 .

4. Freeman S, Herron JC: Evolutionary analysis. 3rd ed. edition., Upper Saddle River; 2004:xiv, 802 p.

5. McKeown T: The origins of human disease. , Basil Blackwell; 1988:vi,233p..

6. Trowell HC, Burkitt DP: Western diseases: their emergence and prevention. London, Edward Arnold; I98I.

7. Lindeberg S: Apparent absence of cerebrocardiovascular disease in Melanesians. Risk factors and nutritional considerations - the Kitava Study. , University of Lund; 1994.

8. Hooper L, Summerbell CD, Higgins JP, Thompson RL, Capps NE, Smith GD, Riemersma RA, Ebrahim S: Dietary fat intake and prevention of cardiovascular disease: systematic review. $\mathrm{Bmj}$ 200I, 322:757-763.

9. Burr ML, Fehily AM, Gilbert JF, Rogers S, Holliday RM, Sweetnam PM, Elwood PC, Deadman NM: Effects of changes in fat, fish, and fibre intakes on death and myocardial reinfarction: diet and reinfarction trial (DART) [see comments]. Lancet 1989, 2:757-76I.

10. Jenkins DJ, Kendall CW, Augustin LS, Martini MC, Axelsen M, Faulkner D, Vidgen E, Parker T, Lau H, Connelly PW, Teitel J, Singer W, Vandenbroucke AC, Leiter LA, Josse RG: Effect of wheat bran on glycemic control and risk factors for cardiovascular disease in type 2 diabetes. Diabetes Care 2002, 25:1522-1528.

II. Masoro Ej: Overview of caloric restriction and ageing. Mech Ageing Dev 2005, I 26:913-922.

12. Bordone L, Guarente L: Calorie restriction, SIRTI and metabolism: understanding longevity. Nat Rev Mol Cell Biol 2005, 6:298-305.

13. Fontana L, Meyer TE, Klein S, Holloszy JO: Long-term calorie restriction is highly effective in reducing the risk for atherosclerosis in humans. Proc Natl Acad Sci U S A 2004, 10 I:6659-6663.

14. Lindeberg S, Söderberg S, Ahrén B, Olsson T: Large differences in serum leptin levels between nonwesternized and westernized populations: the Kitava study. J Intern Med 200I, 249:553-558.
15. Wierup N, Svensson H, Mulder H, Sundler F: The ghrelin cell: a novel developmentally regulated islet cell in the human pancreas. Regul Pept 2002, 107:63-69.

16. McBurney MI, Apps KV, Finegood DT: Splanchnic infusions of short chain fatty acids do not change insulin sensitivity of pigs. J Nutr 1995, I 25:257|-2576.

17. Behme MT: Dietary fish oil enhances insulin sensitivity in miniature pigs. J Nutr 1996, 126:1549-1553.

18. Abdul-Ghani MA, Jenkinson CP, Richardson DK, Tripathy D, DeFronzo RA: Insulin secretion and action in subjects with impaired fasting glucose and impaired glucose tolerance: results from the Veterans Administration Genetic Epidemiology Study. Diabetes 2006, 55: I430-I 435.

19. Katz A, Nambi SS, Mather K, Baron AD, Follmann DA, Sullivan G, Quon MJ: Quantitative insulin sensitivity check index: a simple, accurate method for assessing insulin sensitivity in humans. J Clin Endocrinol Metab 2000, 85:2402-24I0.

20. Brambilla G, Cantafora A: Metabolic and cardiovascular disorders in highly inbred lines for intensive pig farming: how animal welfare evaluation could improve the basic knowledge of human obesity. Ann Ist Super Sanita 2004, 40:24I-244.

21 . Schricker T, Klubien K, Carli F: The independent effect of propofol anesthesia on whole body protein metabolism in humans. Anesthesiology 1999, 90:1636-1642.

22. Dong H, Hyder A, Wang Q, Lu WY: Propofol enhances insulin secretion in INS-I cells (Abstract). Can J Anesth 2004, 5 I:A66.

23. Eckel RH, Grundy SM, Zimmet PZ: The metabolic syndrome. Lancet 2005, 365: 14I 5-I428.

24. Lindeberg S, Eliasson M, Lindahl B, Ahren B: Low serum insulin in traditional Pacific Islanders--the Kitava Study. Metabolism 1999, 48:1216-1219.

25. Huerta MG, Nadler JL: Role of inflammatory pathways in the development and cardiovascular complications of type 2 diabetes. Curr Diab Rep 2002, 2:396-402.

26. Samaras TT, Elrick H, Storms LH: Is short height really a risk factor for coronary heart disease and stroke mortality? A review. Med Sci Monit 2004, I 0:RA63-76.

27. Cordain L, Eades MR, Eades MD: Hyperinsulinemic diseases of civilization: more than just Syndrome X. Comp Biochem Physiol A Mol Integr Physiol 2003, 136:95-I I 2.

28. Heilbronn LK, Clifton PM: C-reactive protein and coronary artery disease: influence of obesity, caloric restriction and weight loss. J Nutr Biochem 2002, 13:316-321.

29. Rikke BA, Johnson TE: Lower body temperature as a potential mechanism of life extension in homeotherms. Exp Gerontol 2004, 39:927-930.

30. Nowak Ronald M: Walker's mammals of the world. 6th ed. edition. Baltimore ; London, Johns Hopkins University Press; 1999:2v., li, 1936p. : ill. : ports. ; $27 \mathrm{~cm}$.

31. Sharma AM, Chetty VT: Obesity, hypertension and insulin resistance. Acta Diabetol 2005, 42 Suppl I:S3-8.

32. Arora SK, McFarlane SI: The case for low carbohydrate diets in diabetes management. Nutr Metab (Lond) 2005, 2:16.

33. Kennedy RL, Chokkalingam K, Farshchi HR: Nutrition in patients with Type 2 diabetes: are low-carbohydrate diets effective, safe or desirable? Diabet Med 2005, 22:82I-832.

34. Hu FB: Protein, body weight, and cardiovascular health. Am J Clin Nutr 2005, 82:242S-247S.

Publish with Bio Med Central and every scientist can read your work free of charge

"BioMed Central will be the most significant development for disseminating the results of biomedical research in our lifetime. "

Sir Paul Nurse, Cancer Research UK

Your research papers will be:

- available free of charge to the entire biomedical community

- peer reviewed and published immediately upon acceptance

- cited in PubMed and archived on PubMed Central

- yours - you keep the copyright
BioMedcentral 